\title{
The Vicious Cycle of Teenage Motherhood: A case study in Eastern Cape, South Africa
}

\author{
T. Pitso \\ J.G. Kheswa \\ Department of Psychology, University of Fort Hare, P. Bag X1314, Alice 5700, RSA \\ Email: tsoloz2002@yahoo.co.uk
}

Doi:10.5901/mjss.2014.v5n10p536

\begin{abstract}
Teenage sexual behaviours link to the theoretical framework of the study that negative psychosocial upbringing could lead to a disastrous adolescence. In turn, this could lead to a chain of teenage motherhood or intergenerational vicious cycle of teenage motherhood which could be caused by the problem of identity confusion. The social exchange theory outlines the reciprocal benefits between the teenage mothers and those who provide the basic needs for them who mostly become old men and their children. The social learning theory of Bandura has outlined that possibility of imitating the behaviours of the parents/guardians by the offspring. The children as the true reflection of how their families are. The socioeconomic challenge of the children of teenage mothers could lead them to be victims of early parenthood due to factors such as poor role-modelling, exposure to destructive activities such as, sexual intercourse and negative peer pressure. The social exchange theory has outlined that the aetiology of teenage motherhood can be traced in the society where the basic needs are not easily acquired. As a result, those who have services monopolise on those who are demanding such services in exchange of favours.
\end{abstract}

Keywords: Teenage, Motherhood, Vicious-cycle

\section{Teenage Sexual Experience}

Six cases of rape are reported in every hour in South Africa and 144 of these cases are reported in a day excluding the unreported cases (Qumbisa, 2013). Furthermore, Women's group estimates are that in every 26 seconds, a woman is raped in South Africa and most of them involve teenage girls. The medical Research Council (MRC) estimates that up to 3600 women could be raped in South Africa every day, in most cases, this involve young girls who are striving to make the ends meet in their daily lives (Jones and Nicholson, 2013). In essence, this brings a number of 25200 a week, 100800 a month and 1209600 a year.

Approximately $30 \%$ of teenagers in South Africa report 'ever having been pregnant', the majority, unplanned (Willan, 2013).This implies that unintended and unplanned pregnancies are forcefully made to these innocent girls. The study by Pitso (2013) found out that most of the pregnant teenagers were aware of the prenatal and postnatal challenges but they were not ready to perform the roles and responsibilities associated with motherhood. Furthermore, this study found out that about $79 \%$ of the pregnant teenagers were not aware of the roles and responsibilities of motherhood but they were not ready to face the psycho-social challenges of motherhood. Papalia, Olds, and Feldman (2009) posited that those teenage mothers who had a negative psycho-social development have a high chance of facing identity crisis/confusion. As a result, they might lead them to being victims of psycho-social interaction such as early pregnancy and end-up giving birth to underprivileged children who might as well be victims of early motherhood.

The teenage mother's total inability to cope may result in high incidence of child abuse, neglect, possible abandonment to the child and even the child exposure to parasitic psychosocial challenges such as being in a relationship with older abusive and deceptive people.

According to Mash, McFarland, McElhaney, Land, and Jodi (2010) teenage motherhood most cases is unplanned; and as a result, teenagers react to the experience differently. The teenager has to come to terms with the unexpected demands of being an adult, and in some cases, she may also have to deal with disapproval and dissatisfaction shown by significant others like parents and relatives. In several studies, teenage mothers reported having felt sad, disappointed, shocked and depressed after their pregnancies were confirmed (De Visser and Le Roux, 1996). Furthermore, most teenagers started by denying the pregnancy at first, before they could inform their parents who, in most cases received the news with anger and disappointment.

\section{The Prevalence of Teenage Motherhood}

According to Statistics South Africa (2007) the percentage of teenage motherhood was at 11.2 percent (66000) in 2002 
while in 2004 it escalated to17.4 percent. Furthermore, to show that teenage motherhood increases, Sosibo (2007) articulated that the media reports of 2006 indicates that in South Africa, over 72000 girls aged between 13 and 19 years were pregnant. A Human Sciences Research Council (HSRC) study showed that even though total fertility rates in South Africa have been declining over the past few decades, teenage fertility has, in contrast, increased in all race groups except in the case of Indians (Makiwane and Udjo, 2006). One suggestion here is that overall fertility has been accompanied by a shift in childbearing towards younger women.

Research by Lilaroja (2010) found that, annually, 13 million children are born to women under age 20 worldwide, more than $90 \%$ in developing countries. This has an impact not only on women's health, but on the socio-economic status and general well-being of the population. Furthermore, Panday, Makiwane, Ranchod and Letswalo (2009) posited that teenage motherhood has grown in significance as a social construct and come to represent one of several indicators of burgeoning adolescent delinquency, sexual permissiveness and moral decay.

\section{The Impact of Teenage Motherhood}

Teenage-motherhood could bring a myriad of problems which could be psychological, physiological and socioeconomical. Teenage mothers are unaware of some consequences of early motherhood, namely, poverty, reduced job opportunities and low self-esteem. Teenage mothers believe that children are important for the security and continuation of the family, family possessions and family name, hence cultural values contribute to non-utilization of condoms when engaging in sexual activities (Ziyane and Ehlers, 2006).

Teenage-motherhood is more likely to result in pregnancy complications that can lead to the death(s) of the young mother and/or her baby. Other associated factors include increased risk of infant morbidity, and a range of adverse social, psychological and economic effects on the young mother.

\section{Single-Parent Households and Child-Headed Family}

According to Holborn and Eddy (2011) research on fractured families reveals that most of the children stay with their mothers. The implication being that the greatest number of children does not get enough parental comfort because of the single parenthood which does not address their problems holistically. Only 35\% of children were living with both their biological parents in 2008. Some $40 \%$ were living with their mother only and $2.8 \%$ with their father only, which leaves $22.6 \%$ of children who were living with neither of their biological parents.

The study by Holborn and Eddy (2011) also emphasises that the effect of the HIVIAIDS pandemic is mostly caused by risky sexual behavioural practice by parents and results in the increasing numbers of orphans and child-headed households. When girls grow up in a single parenthood household, it creates parental imbalance of nurturing the child fully.

\section{Dysfunctional Family}

Lack of parental figures especially the father leaves the teenage girls with delinquent behaviours, psychological disturbance, low self-esteem, early home leaving, poor self-restraint and social adjustment among teenagers (East and Shi, 1997). In addition, this situation of a dysfunctional family leaves the girl teenage girl in a vulnerable position with no one to provide a shoulder to cry on. Macleod (2003) posited that sometimes teen mothers have fear participating in class discussions for instance during "Life Orientation" programmes. For example, when topics like 'teenage pregnancy' arose, the teen mothers become particularly uncomfortable that everybody was talking about their situation.

\section{Age Desperate Relationships}

According to IRIN Africa (2011) the age-gap and experience of the teenage mothers' partners play a major role in terms of influencing the nature of their relationship. Old men are commonly in control of such a relationship with teenage girls and they are the one to determine whether to use a condom when having sex or not, even the issue of moving in together (cohabitation) since they are the basic needs providers and at times they become violent if the teenage mothers are not complying. Mature adult people can easily manipulate young teenagers who are still struggling to discover their own personality by dominating them to an extent that they are unable to negotiate safe sex (IRIN Africa, 2011). Such teenagers may find themselves trapped in abusive sexual relationships because they are being showered with gifts. From this type of sexual practice, Meade, Kershaw, and Ickovics (2008) found that majority of girls end up in transactional sex 
(prostitution) especially when they come from poverty- stricken families. According to Nzouankeu (2010) the study on teenage motherhood found that, compared with non-abused mothers, adolescent mothers initiated sex earlier, had sex with much older partners, and engaged in riskier, more frequent, and promiscuous sex. In addition, Garenne, Tollman, Kahn, Collins, and Ngwenya (2001) posited that teenage mothers are also more likely to carry the baby for nine months rather than have an abortion. In addition, men older than high school age fathered 77 percent of all births to high schoolaged girls (ages 16-18), and 51 percent of births to girls (15 and younger). Men over 25 years of age fathered twice as many children of teenage mothers than boys under the age of 18, and men over age 20 fathered five times as many children of teenage girls under 15.

\section{The Vicious-Cycle of Teenage Motherhood}

Lilaroja (2010) found that family dysfunction has enduring and unfavourable health consequences for women during the adolescent years, the childbearing years, and beyond. Furthermore, when the family environment does not include adverse childhood experiences, becoming pregnant as an adolescent does not appear to raise the likelihood of longterm, negative psychosocial consequences. In addition to that, Oke (2010) found that a girl is also more likely to become a teenage parent if her mother or older sister gave birth in her teens and the cycle will follow the trend of one generation to the other. As a result, the vicious cycle of teenage motherhood is formed.

\section{Findings}

Based on the findings, the following themes:

\subsection{Marital Status of the teenage mothers}

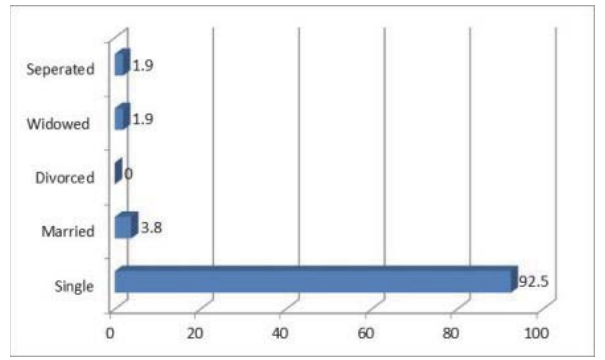

Source: Printout of a figure derived from the data of this study

The marital statuses of the respondents were established, as it would indicate the level of early marriage in the society. Of the 106 respondents, $92.5 \%(n=98)$ indicated that they were single; $3.8 \%(n=4)$ stated that they were married; $0 \%$ $(n=0)$ were divorced; $1.9 \%(n=2)$ were widowed while $1.9 \%(n=2)$ confirmed to have been separated. The implication of this finding could be that the respondents who were married had been deprived of their education. Marriage at this age is a risk factor to adolescents since their bodies are still developing, and they have to depend on the partner for the rest of their lives to meet the challenges of being mothers and wives unless they go to school again. Nasoro (2003) maintains that parents should be educated on the importance of striving for the education of their female children and postpone their marriage until they are older and responsible.

\subsection{Respondents' live with}

\begin{tabular}{|l|c|c|}
\hline Living With ... & Frequency & Percent \\
\hline Single parent & 44 & $41.5 \%$ \\
\hline Both parents & 28 & $26.4 \%$ \\
\hline Mother and step-father & 9 & $8.5 \%$ \\
\hline Father and step-mother & 11 & $10.4 \%$ \\
\hline Other (aunt, uncle etc.) & 10 & $9.4 \%$ \\
\hline Boyfriend & 4 & $3.8 \%$ \\
\hline Total & 106 & $100 \%$ \\
\hline
\end{tabular}

Source: Printout of a table derived from the data of this study 
From the table above, of the 106 respondents, $41.5 \%$ ( $n=44)$ indicated that they live with a single parent; while $26.4 \%$ $(n=28)$ live with both parents; and $8.5 \%(n=9)$ lived with their mothers and the step-fathers. Furthermore, $10.4 \%(n=11)$ indicated that they live with their fathers and the step-mothers; $9.4 \%(n=10)$ lived with their aunts or uncles; and 3.8\% $(n=4)$ confirmed that they lived with their boyfriends. The finding of this research is that most of the respondents were living with their single parents, who in most cases happen to be their mothers who gave birth to them at the age of teenage-hood. This indicated that most of the families were not "intact" because the respondents did not have both parents to nurture them from paternity and maternity levels. As a result, the vicious-cycle of teenage motherhood could emerge.

\subsection{Marital status of the teenage mothers' biological parents}

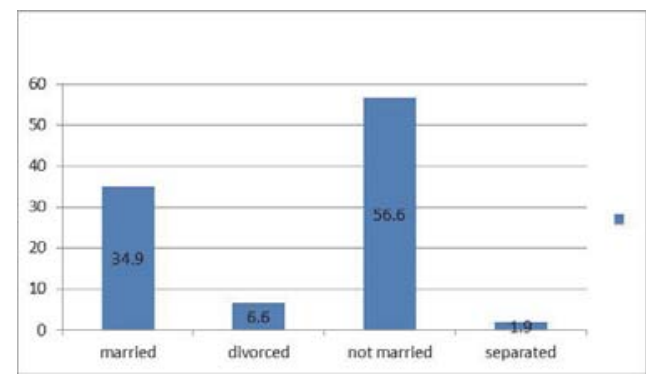

Source: Printout of a figure derived from the data of this study

The respondents were asked to indicate their biological parents' marital status, as it would indicate the nature of family that the respondents originate from and the influences that such a family can have on the respondents in terms of identity and readiness for motherhood. The Figure above shows that $34.9 \%(n=37)$ of the respondents parents are married; $6.6 \%(n=7)$ are divorced; $56.6 \%(n=60)$ are not married at all; and $1.9 \%(n=2)$ are separated. The information displayed in the figure above confirms that most of the pregnant teenagers come from single parents who were never got married before and this might be due to their age motherhood. According to Hetherington, Parke, Gauvain, and Locke (2006) the attachment theory by Bowlby showed that a family with a single parent can bring imbalance in terms of attachment and upbringing of the off-springs. As a result, children may not develop full psycho-social and psycho-sexual skills to combat the daily challenges of life and end up falling into early parenthood. As result, they might fail to perform their roles and responsibilities of parenthood and their off-springs falling into early parenthood as well.

\subsection{Education level of the teenage mothers' parents}

\begin{tabular}{|l|c|c|}
\hline & Frequency & Percentage \\
\hline Pre school & 7 & 6.6 \\
\hline primary & 16 & 15.1 \\
\hline High school & 62 & 58.5 \\
\hline tertiary & 21 & 19.8 \\
\hline Total & 106 & 100 \\
\hline
\end{tabular}

Source: Printout of a table derived from the data of this study

According to the table above, respondents' parents, $6.6 \%(n=7)$ had Pre-school education; $15.1 \%(n=16)$ had primary school education; $58.5 \%(n=62)$ had high education, and $19.8 \%(n=21)$ had tertiary education. The information provided by the table above shows that $(\mathrm{n}=85)$ which make $80.2 \%$ of the parents of the respondents went as far as high school in terms of education and only $(n=21)$ which is $19.8 \%$ managed to get tertiary education. The research by Philemon (2007) found out that the level of education of the parents has an influence on the upbringing of the children and low education means few opportunities for the offspring to survive and vice versa. In essence, lack of knowledge, both academic and the sexual and reproductive health one can bring an ample of problems such as being involved in uninformed decisionmaking, being victims of myths and misconceptions and even lack of exposure to life opportunities. As result, dependency-syndrome will emerge and this leaves them in a susceptible situation of exploitation. 


\subsection{Teenage mothers feel insecure to be mothers}

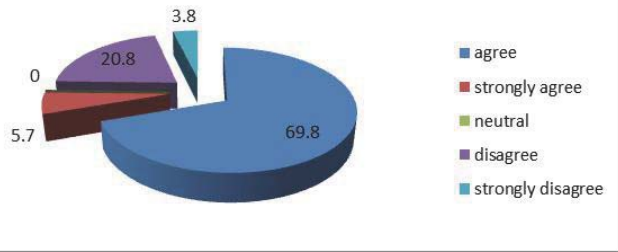

Source: Printout of a figure derived from the data of this study

The above figure shows that out of 106 respondents, $69.8 \%(n=74)$ agreed that they feel insecure to be mothers; $5.7 \%$ $(n=6)$ strongly agreed ; $0 \%(n=0)$ showed neutrality ; $20.8 \%(n=22)$ disagreed that they felt insecure to be mothers ; and $3.8 \%(n=4)$ strongly disagreed about feeling insecure to being mothers. $75.5 \%$ of the respondents indicated their insecurity to be mothers while only $24.6 \%$ indicated that they were not insecure to be mothers. According to Pitso (2013) girls who cannot be resilient to challenges become victims of such challenges portray a low self-esteem and as a result, they will always feel insecure to their status such as being mothers.

\section{Conclusion}

Teenage mothers originate from the socio-economically challenged families whereby the caregivers did not provide enough resources for the survival of the offspring due to their low income and level of education. These families have been found to be headed by single parents. In most cases teenagers are heading their families due to the absence of the parents which is caused by death or abandonment. The issue has been perpetual since time immemorial but the extended families used to intervene and bail the off-springs out of the situation. This issue can also be justified by the escalating statistics of street kids, orphanage and foster care. The impact of the

\section{References}

De Visser, J. \& Le Roux, T. (1996). The experience of teenage pregnancy in Knoppieslaagte. South African Journal of Sociology, 27 (3), 98 - 105.

East, P. L. and Shi, C. R. (1997). Pregnant and parenting adolescents and their younger sisters: The influence of relationship qualities for younger sister outcomes. Journal of Developmental \& Behavioural Paediatrics, 18, 84-90.

Garenne, M., Tollman, S., Kahn, K., Collins, T., \& Ngwenya, S. (2001).Understanding marital and premarital fertility in rural South Africa. Journal of Southern African Studies, 27, 277-290.

Hetherington, E.M, Parke, R.S, Gauvain, M and Locke, V.O. (2006). Child Psychology, A Contemporary Viewpoint. McGraw: New York.

Holborn, L, and Eddy, G. (2011).First steps to healing the South African family. A research paper by the South African Institute of race relations sponsored by Donaldson Trust .Marshalltown.

IRIN Africa (2011). SOUTH AFRICA, Teenage pregnancy figures cause alarm. SA

Jones. M and Nicholson, Z. (2013). Up to 3600 rapes in South Africa every day. February $8^{\text {th }} 2013,07: 47$ a.m.

Lilaroja (2010). Schools 'push teen mothers to be dropouts', Life chances of teenage mothers and their children threatened by barriers to education. Sunday 14 March 2010.

Macleod, C. (2003). Teenage pregnancy and the construction of adolescence scientific literature in South Africa. Rhodes University. South Africa.

Makiwane, M. and Udjo, E. (2006).Is the Child Support Grant associated with an Increase in Teenage Fertility in South Africa? Evidence from National Surveys and Administrative Data. Pretoria: Human Sciences Research Council.

Mash. A, J. P., McFarland, P., McElhaney, C., Land, K. B.,Jodl, D. J., (2010) School-based prevention of teenage pregnancy and school dropout: Process evaluation of the national replication of the Teen.

Meade, C.S., Kershaw, T.S and Ickovics, J.R. (2008). The intergenerational cycle of teenage motherhood. An ecological approach. Heath psychology $27 . n 042008$.

Nasoro, M. (2003) Sexual behaviour: contraceptive awareness and use among pregnant adolescents attending clinics in Dar-es-Salaam, Tanzania. Unpublished dissertation. Muhimbili University of Health and Allied Sciences. Dar-es-Salaam, Tanzania.

Nzouankeu, A, M. (2010). The down side to the government's baby grant. 10 August 2010. SA.

Oke, Y.F. (2010). Poverty and Teenage Pregnancy: The Dynamics in Developing Countries Vol. 2, No. 5, pp. 63-66, 2010 NIGERIA.

Panday, S., Makiwane, M., Ranchod, C., and Letsoalo, T. (2009). Teenage Pregnancy In South Africa. SA.

Papalia, D.E, Olds, S.W. \& Feldman, R.D. (2009). Human - Development .Eleventh Edition. McGraw-Hill Companies, Inc: Boston.

Philemon, M.N, (2007). Factors contributing to high adolescent pregnancy rate in Kinondoni Municipality, Dar-es-salaam, Tanzania, UNISA (University of South Africa).

Pitso, T. (2013). Pregnant teenagers' Readiness for motherhood: A quantitative study in Nkonkobe Municipality, Eastern Cape Region. University of Fort Hare. South Africa.

Qumbisa, N. (2013). The abnormal normality of rape in South Africa. 30th September 2013.

Sosibo, K. (2007). Sweet 16 Young Mamas.Mail\& Guardian, p.12, March, 9 to 15.

STATITSICS SOUTH AFRICA Community Survey (2007): Statistical Release Basic Results Municipalities / Statistics South Africa. Pretoria.

Willan. S. (2013) A Review of Teenage Pregnancy in South Africa - Experiences of Schooling, and Knowledge and Access to Sexual and Reproductive Health Services. Partners in Sexual Health (PSH). South Africa.

Ziyane, I.S. and Ehlers, V.J. (2006). Swazi youth attitudes and perceptions concerning adolescents' pregnancies and contraception. Health S.A. Gesondheid, 11(1):3142. 